\title{
Characterization of a Functional NTPDase in the Endoplasmic Reticulum of Rat Submandibular Salivary Gland
}

\author{
M. A. OSTUNI ${ }^{1,2}$, P. EGIDO ${ }^{2}$, G. PERANZI ${ }^{1}$, G. L. ALONSO ${ }^{2}$, J.-J. LACAPERE ${ }^{1}$, \\ D. A. GONZALEZ ${ }^{2}$
}

${ }^{1}$ INSERM U773, Centre de Recherche Biomédicale Bichat-Beaujon (CRB3), Université Paris, Paris, France, ${ }^{2}$ Cátedra de Biofísica, Facultad de Odontología, Universidad de Buenos Aires, Buenos Aires, Argentina

Received September 10, 2008

Accepted October 16, 2008

On-line December 17, 2008

\begin{abstract}
Summary
Nucleotidase activity and Ca-uptake were characterized in endoplasmic reticulum (ER) enriched rat submandibular gland (SMG) microsomal preparations. (i) Ca-uptake had characteristics of an ER Ca-ATPase. (ii) Nucleotidase activity was equally stimulated by calcium, magnesium and manganese, but with different $\mathrm{Km}$ values. (iii) Specific inhibitors of P-type Ca-ATPases were ineffective on nucleotidase activity, demonstrating that this activity was not related to calcium uptake and did not correspond to classical $\mathrm{Ca}^{2+}$ pumps. (iv) ATP and UTP were more efficient substrates, whereas ADP and UDP were hydrolyzed at significantly slower rate. (v) Nucleotidase activity was sensitive to mild detergent solubilization and insensitive to ionophore addition. (vi) Nucleotidase activity was strongly inhibited by suramin, a nucleoside triphosphate diphosphohydrolase (NTPDase) inhibitor. (vii) Nucleotidase activity exponentially diminished as function of time. All these observations are consistent with a NTPDase identity. The presence of a NTPDase was demonstrated by immunohistochemistry in rat SMG. Immunoreactivity was stronger in ductal cells than in mucous and serous acini. Although this enzyme was observed in the plasma membrane, colocalization with the ER marker calnexin revealed a specific subcellular localization in this organelle of all three types of cell. The putative function of this NTPDase activity in salivary glands is discussed.
\end{abstract}

\section{Key words}

Apyrase • CD39 • Ca-uptake • ATPase activity • Submandibular gland

\section{Corresponding author}

M. A. Ostuni, INSERM U773, Centre de Recherche Biomédicale Bichat-Beaujon (CRB3), 16, rue Henri Huchard, 75870 Paris Cedex, France. Fax: (+33) 15727 7485. E-mail: mariano.ostuni@inserm.fr

\section{Introduction}

Submandibular glands (SMG) belong to the major salivary gland group, with important functions involved in the oral health and the digestion process. They are widely used as a model to study the secretory mechanisms in the epithelial cells. Regulation of salivary secretion is complex and secretory agents usually act by cAMP and $\mathrm{Ca}^{2+}$ pathways, which could regulate the same process with opposite or synergic results.

The $\mathrm{Ca}^{2+}$ pathway implies the fine-tuning regulation of cytosolic calcium levels. $\mathrm{Ca}^{2+}$ influx from the extracellular liquid and $\mathrm{Ca}^{2+}$ release from intracellular calcium stores are strongly related with the cation extrusion and the stores refilling. Several pumps and calcium channels have been identified in submandibular glands. Muallem and coworkers have identified in the rat submandibular gland different calcium ATPases as the plasma membrane Ca-ATPase (PMCA) and the sarco-endoplasmic reticulum CaATPase (SERCA) (Lee et al. 1997a), and calcium channels like the $\mathrm{IP}_{3}$-sensitive and the ryanodynesensitive (Lee et al. 1997b). 
The functional characterization of the SERCA was usually addressed by measuring the enzymatic activity and the ionic transport in submandibular endoplasmic reticulum microsomes (Alonso et al. 1971, Hurley and Martínez 1985, 1986, Hurley and Ryan 1988), but a clear correlation between $\mathrm{Ca}^{2+}$ uptake and ATPase activity was never well established. At present the question remains what is the actual identity of the enzymes that hydrolyze ATP in those microsomes.

Another class of ATP hydrolyzing enzymes is the family of ecto-nucleoside triphosphate diphosphohydrolases (NTDPases) that hydrolyze ATP and other nucleotides with largely higher hydrolysis rate than the Ca-ATPase pumps, but without coupled cation transport (for detailed review see Plesner 1995, Robson et al. 2006). At present, eight members of this family were identified, which are located to the plasma membrane and/or to intracellular membranes (Robson et al. 2006).

NTPDases are ubiquitous in eukaryotic cells but their functions are not fully understood. Cumulate evidence supports the involvement of these enzymes in the regulation of nucleotide concentration and adenosine recycling process. Furthermore, their spatial and temporal expression in several cell types could be at the origin of different pathophysiological processes (reviewed in Robson et al. 2006).

Several articles characterizing an NTPDase like activity in the rat parotid gland were published (Dowd et al. 1989, 1993, 1996, 1999, Teo et al. 1993, Murphy et al. 1994), but there are only a few papers concerning this kind of activity in rat submandibular gland (Valenzuela et al. 1989, Murphy et al. 1994)

In this work we characterize an ATPase activity of endoplasmic reticulum microsomes from rat submandibular gland, which has the characteristics of an ecto-nucleotidase activity and that it is not related to calcium uptake. We also identify the cellular and subcellular localization of a NTPDase immunoreactivity in this gland.

\section{Methods}

\section{Animals}

Male Wistar rats weighing 250-280 g were fed with standard chow diet and water ad libitum, and kept with $12 \mathrm{~h}$ light / $12 \mathrm{~h}$ dark period. They were treated in accordance with the European Convention for the Protection of Vertebrate Animals used for Experimental and other Scientific Purposes (CETS 123).

\section{Microsomes preparation}

Microsomes preparation protocol was modified from that previously described by Hurley and Martinez (1986). Briefly, rats were allowed free access to standard chow pellets and water except for the night before sacrifice when only food was withheld. For each tissue preparation 2-4 rats were deeply anaesthetized with ether and exsanguinated via the abdominal aorta. The submandibular glands were removed, separated from the adjoining sublingual glands, weighed, minced on ice and homogenized in cold buffer (10 mM HEPES, pH 7.0, 0.3 $\mathrm{M}$ sucrose and $1 \mathrm{mM}$ of the protease inhibitor PMSF) using a teflon and glass homogenizer. The homogenate was centrifuged for $2 \mathrm{~min}$ at $1000 \mathrm{x} \mathrm{g}$ to remove nuclei and cell debris. Supernatant was centrifuged for $20 \mathrm{~min}$ at $10,000 \mathrm{x}$, the pellet containing mitochondrial fraction was discarded and resulting supernatant was centrifuged for $30 \mathrm{~min}$ at $27,000 \mathrm{x}$. The final pellet was resuspended in the same buffer and proteins were quantified using the dye-binding BioRad assay.

\section{Electron microscopy}

Microsome preparation was fixed in $2.5 \%$ glutaraldehyde during $60 \mathrm{~min}$ at room temperature and postfixed in $1 \%$ osmium tetroxide for $60 \mathrm{~min}$. It was dehydrated and embedded in LX-112 resin and sections were contrasted with $2 \%$ uranyl acetate and observed in a JEOL 1200 EX electron microscope operated at $80 \mathrm{kV}$ accelerated voltage.

\section{Electrophoresis and Western blotting}

SDS-polyacrylamide gel electrophoresis was performed according to Laemmli (1970). Proteins (15 $\mu \mathrm{g}$ per lane) were separated on $10 \%$ polyacrylamide gel under non-reducing conditions. They were transferred to $0.45 \mu \mathrm{m}$ pore nitrocellulose membranes (Sartorius AG, Göttingen, Germany) and probed with monoclonal antihNTPDase1 antibody (BU61 clone, Ancell, Bayport, MN, USA) (1:750 dilution); or with a rabbit anti-calnexin monoclonal antibody (Becton Dickinson, Le Pont de Claix, France). (1:4000 dilution). Bands were visualized using peroxidase-conjugated anti-mouse or anti-rabbit IgG respectively (Sigma, Saint-Quentin Fallavier, France) and the Pierce ECL Western blotting substrate (Thermo Scientific, Rockford, IL, USA).

\section{Deglycosylation}

Microsome preparations were subjected to deglycosylation using PNGase F (New England Biolab, 
Ipswich, MA, USA) following manufacturer instructions.

\section{ATPase activity}

The microsomal ATPase activity was measured at $\mathrm{pH} 7.2$ and $37{ }^{\circ} \mathrm{C}$ following $\mathrm{Pi}$ liberation. The media contained $50 \mathrm{mM}$ MOPS-Tris, $\mathrm{pH} 7.2,100 \mathrm{mM} \mathrm{KCl}$, $3 \mathrm{mM}$ ATP and different amounts of $\mathrm{CaCl}_{2}$ or $\mathrm{MgCl}_{2}$, and EGTA to obtain the desired cation concentration. Reactions were started by addition of $0.1 \mathrm{mg}$ vesicular protein per $\mathrm{ml}$. After $2 \mathrm{~min}$ incubations the reactions were stopped by addition of cold trichloroacetic acid at $5 \%$ final concentration. Pi production was determined by a colorimetric method (Baginski et al. 1967). Free cation concentrations were calculated as previously described (Fabiato and Fabiato 1979).

\section{${ }^{45}$ Ca]Ca-uptake}

Ca-uptake was measured in $1 \mathrm{ml}$ of medium of the following composition: $100 \mathrm{mM} \mathrm{KCl}, 50 \mathrm{mM}$ MOPS/Tris, pH 7.2, $3 \mathrm{mM}$ ATP, $3 \mathrm{mM} \mathrm{MgCl} 2,0.1 \mathrm{mM}$ $\mathrm{CaCl}_{2}$, also containing $1500 \pm 500 \mathrm{cpm} / \mathrm{nmol}$ of $\left[{ }^{45} \mathrm{Ca}\right]$ (New England Nuclear, Boston, MA, USA), and $0.1 \mathrm{mg}$ of membrane protein. The reaction mixture lacking membrane proteins was preincubated for $5 \mathrm{~min}$ at $37^{\circ} \mathrm{C}$. Ca-uptake was started by addition of membrane proteins and aliquots of the reaction mixture were passed through Millipore filters $(0.45 \mu \mathrm{m}$ pore diameter $)$ at the given time periods. The filters were immediately washed with $5 \mathrm{ml}$ of $3 \mathrm{mM} \mathrm{LaCl}_{3}$ in order to diminish the unspecific binding. Radioactivity was determined by liquid scintillation counting in a toluene-based scintillation cocktail.

\section{Immunohistochemistry}

Submandibular glands from four rats were removed and cleaned from connective tissue. They were immediately fixed in $4 \%$ paraformaldehyde during $4 \mathrm{~h}$ at room temperature and embedded in paraffin. Paraffin sections were rehydrated and endogenous peroxidase activity was inactivated by the peroxidaseantiperoxidase (PAP) technique. Sections were incubated with a mouse anti-human NTPDase1 (hNTPDase1) monoclonal antibody (BU61 clone, 1:100 dilution, Ancell, Bayport, MN, USA) overnight at $4{ }^{\circ} \mathrm{C}$. Peroxidase complexed secondary antibody was purchased from Dakopatts Ltd. (Trappes, France). Sections were counterstained with Mayer's hematoxylin (E.M.S.) (Euromedex, Souffelweyersheim, France).

\section{Colocalization studies}

Paraffin sections for confocal microscopy were rehydrated and incubated with a rabbit anti-calnexin monoclonal antibody (1:100) for $1 \mathrm{~h}$ (Becton Dickinson, Le Pont de Claix, France). After washing, sections were incubated with a secondary anti-rabbit immunoglobulin antibody coupled with ALEXA Fluor 488 (1:200) (Molecular Probes, OR, USA) and then incubated overnight at $4{ }^{\circ} \mathrm{C}$ with the anti-hNTPDase1 antibody (1:100). Following the second washing, secondary antimouse immunoglobulins antibody coupled with ALEXA Fluor 546 (Molecular Probes) was applied for $60 \mathrm{~min}$ (1:150 dilution). After several washes, slides were covered with a hydrophilic and antifading mounting media (Fluoromount G, E.M.S.). Final observations were made with a Zeiss Axiovert 200M confocal microscope with a $63 x$ oil immersion objective. LSM 510 image software (Heidelberg, Germany) was used to select observation fields (identical intensities profile of each fluorochrome), to collect the results (histograms, fluorograms, colocalizations of both dyes), to derive data recording and to perform the analysis. Step size for the sectioning was $0.4 \mu \mathrm{m}$ for the deconvolved images with a pinhole value fixed at $1 \mu \mathrm{m}$. Similar incubations without the primary antibody were also performed as negative controls.

\section{Reagents and solutions}

$\mathrm{C}_{12} \mathrm{E}_{8}$ was purchased from Calbiochem (La Jolla, CA, USA). Unless otherwise noted, all other reagents were purchased from Sigma Chemical Co. (St. Louis, MO, USA).

\section{Statistics}

Data are presented as the mean \pm S.E.M. Experimental data were evaluated using one-way ANOVA. Scheffe's homogeneity test was performed in order to determinate differences between means of each experimental group and control counterpart. Differences were considered significant for $\mathrm{p}<0.05$.

\section{Results}

\section{Electron microscopy and Western blot}

Figure 1a shows typical image of section from microsomal preparation embedded in resin. Vesicles surrounded by large dots correspond to ribosomes with typical characteristics of rough ER microsomes. Dotted surfaces were also observed and corresponded to surfaces 
of vesicles that have not been sectioned. It has to be mentioned that neither mitochondria nor mitochondrial fragments were observed in these microsomal preparations.

The ER origin of these microsomes was confirmed by Western blot with the presence of a characteristic band of $88 \mathrm{kDa}$ that corresponds to the ER specific protein calnexin (Fig. 1b).

\section{$\left.{ }^{45} \mathrm{Ca}\right] \mathrm{Ca}$ uptake}

Figures 1c and 1d show time-dependent Ca uptake by SMG microsomes. Figure 1c demonstrates ATP dependence of this uptake, resulting in an increase of calcium inside the vesicles, observed only in the presence of ATP. A fast release of $\mathrm{Ca}^{2+}$ was triggered by addition of $\mathrm{Ca}^{2+}$ ionophore $\mathrm{A} 23187$.

The effect of two SERCA inhibitors on Ca-uptake are shown in the Figure 1d. Thapsigargin and sodium orthovanadate diminished the $\mathrm{Ca}^{2+}$ uptake to SMG microsomes by about $90 \%$. The mitochondrial Cauniporter inhibitor ruthenium red and the PMCA inhibitor compound 48/80 had no effect on SMG microsomes $\mathrm{Ca}^{2+}$ uptake (data not shown). These are the first results about the action of ATPase inhibitors on the rat submandibular $\mathrm{Ca}^{2+}$ uptake. They confirm the microsomal origin of the ER membranes while minimizing the possibility of mitochondrial or plasma membrane contamination.

\section{ATPase activity}

To functionally characterize the ATPase activity in our micromal preparation, we tested: i) the dependence on $\mathrm{Ca}^{2+}$ and/or $\mathrm{Mg}^{2+}$, (ii) the sensitivity to specific inhibitors of P-type, F-type, and V-type ATPases, (iii) the substrate preference pattern, (iv) the sensitivity to the action of detergents and (v) the dependence on incubation time.

Figure 2a shows ATPase activity of SMG microsomes as function of either free $\mathrm{Mg}^{2+}$ (with no added calcium) or free $\mathrm{Ca}^{2+}$ (without added magnesium). Maximal activities were similar for both conditions (around $1 \mu \mathrm{mol}$ Pi produced/mg protein/min), but the $\mathrm{Km}$ values calculated from plots were different with values of $28 \pm 5 \mu \mathrm{M}$ and $320 \pm 51 \mu \mathrm{M}$ for $\mathrm{Ca}^{2+}$ and $\mathrm{Mg}^{2+}$, respectively. ATPase activity was also stimulated by $\mathrm{Mn}^{2+}$ (open squares). Maximal activity was reached in the presence of millimolar concentrations of $\mathrm{Ca}^{2+}$ or $\mathrm{Mg}^{2+}$ irrespective of other cation concentrations (data not shown).
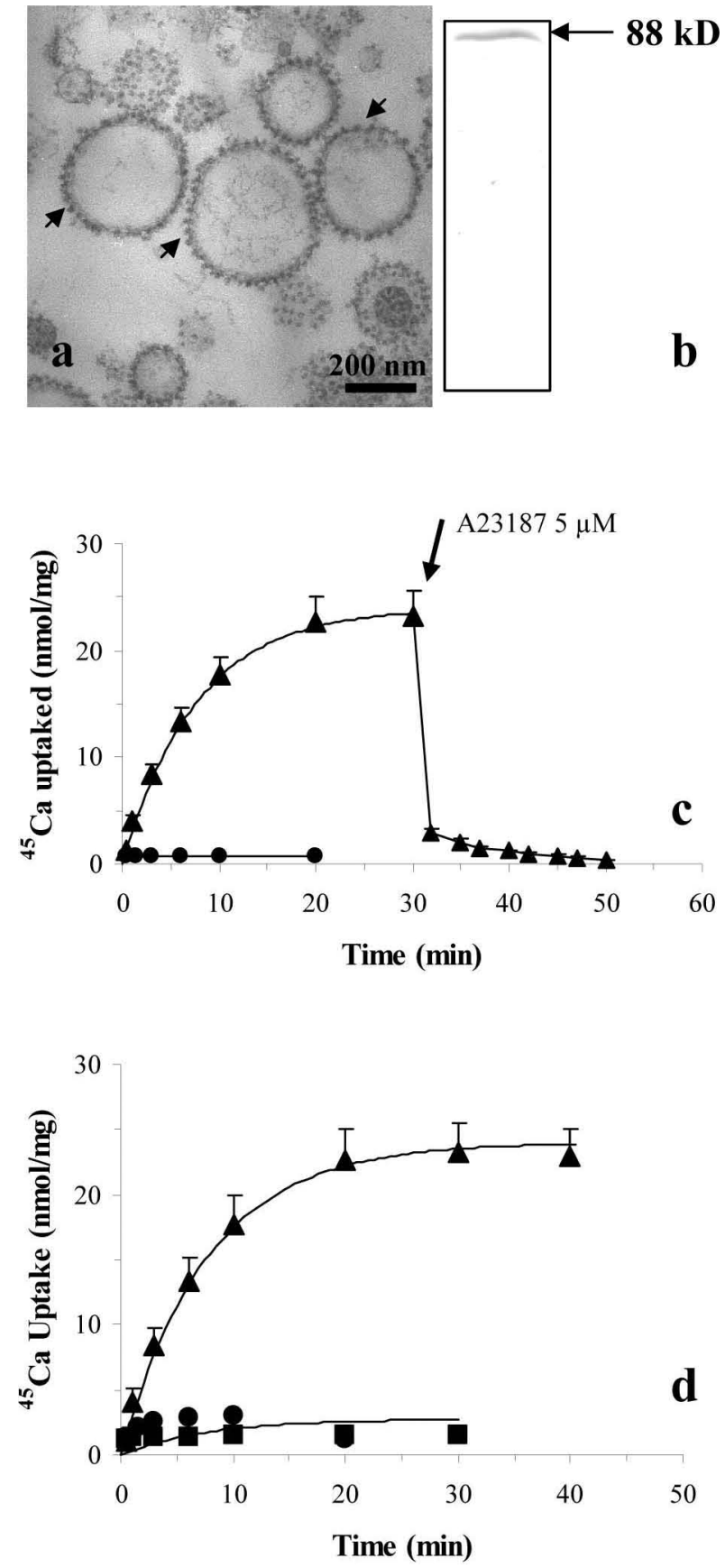

Fig. 1. $E R$ origin and calcium uptake by rat submandibular microsomes (a) Electron micrograph of a thin section of the microsome preparation showed typical rough microsomes (arrows indicated the ribosomes bound to the vesicles, bar= $200 \mathrm{~nm}$ ). (b) Western blot for identification of Calnexin. Immunoreactivity of microsomes from rat submandibular endoplasmic reticulum with a rabbit anti-calnexin monoclonal antibody. (c) Calcium uptake was measured at $37^{\circ} \mathrm{C}, \mathrm{pH} 7.2$, $50 \mu \mathrm{M}{ }^{45} \mathrm{Ca}\left(\mathrm{CaCl}_{2}\right), 100 \mathrm{mM} \mathrm{KCl}, 3 \mathrm{mM} \mathrm{MgCl}$, with (triangles) or without (circles) $3 \mathrm{mM}$ ATP. As indicated by arrow, $5 \mu \mathrm{M}$ calcium ionophore A23187 was added. (d) Experiments were made with identical control condition (triangles) but in the presence of $1 \mathrm{mM}$ sodium orthovanadate (squares) or $2 \mu \mathrm{M}$ thapsigargin (circles). Each point is a result of at least 5 independent experiments. Results are expressed as mean \pm S.E.M. 
Table 1. Effects of inhibitors on ATP hydrolysis by rat submandibular microsomes.

\section{Inhibitor \\ ATPase activity \\ (\% of control)}

$\begin{array}{lc}\text { Thapsigargin }(2 \mu M) & 89.7 \pm 12.6 \\ \text { Sodium orthovanadate }(1 \mathrm{mM}) & 89.8 \pm 7.8 \\ \text { Ouabain }(0.1 \mathrm{mM}) & 95.5 \pm 10.5 \\ \text { Compound } 48 / 80(1 \mathrm{mg} / \mathrm{ml}) & 89.3 \pm 9.3 \\ \text { Sodium azide }(10 \mathrm{mM}) & 67.4 \pm 11.5^{*} \\ \text { Suramin }(3 \mathrm{mM}) & 19.7 \pm 2.0^{* *} \\ \text { Suramin }(3 \mathrm{mM})+\text { sodium } & 13.4 \pm 2.9 * * \\ \text { orthovanadate }(1 \mathrm{mM}) & 28.0 \pm 2.0^{* *} \\ C_{12} E_{8}(\text { detergent/protein }=3 \mathrm{w} / \mathrm{w}) & 98.0 \pm 4.5 \\ \text { Ionophore }(A 231875 \mu \mathrm{M})\end{array}$

Control ATPase activity (100 \%) was $1.24 \pm 0.09 \mu \mathrm{mol} \mathrm{Pi} / \mathrm{mg}$ protein/min. Results are expressed as mean \pm S.E.M. $(n=5)$. Data were analyzed by one-way ANOVA. $* \mathrm{p}<0.05, * * \mathrm{p}<0.01$.

Table 1 shows the effect of different ATPase inhibitors. No significant inhibition of ATPase activity was obtained by the SERCA inhibitor thapsigargin, the P-type ATPases inhibitor sodium orthovanadate, the PMCA inhibitor compound $48 / 80$, or the $\mathrm{Na} / \mathrm{K}$ ATPase inhibitor ouabain. However, sodium azide, an unspecific NTPDase inhibitor (Knowles and Nagy 1999, Schetinger et al. 2001), slightly diminished ATPase activity (67.4\% of control), while suramin, a NTPDase inhibitor (Iqbal et al. 2005), produced a strong inhibition of this activity. Figure $2 \mathrm{~b}$ shows the concentration-dependent inhibition profile from which $\mathrm{IC}_{50}$ could be calculated giving values of $55 \pm 10 \mu \mathrm{M}$ and $585 \pm 160 \mu \mathrm{M}$ for suramin and sodium azide, respectively. The simultaneous addition of suramin and sodium orthovanadate at saturating concentrations produced an additional $5 \%$ inhibition, whereas addition of calcium ionophore A23187 did not change ATPase activity.

Hydrolysis of different tri- and dinucleotides are presented in Figure 2c. The SMG microsomes nucleotidase activity is principally a tri-nucleotidase activity. ATP and UTP are largely hydrolyzed compared to ADP or UDP. ATP/ADP and UTP/UDP hydrolysis ratio are 4.39 and 4.93, respectively. Figure $2 \mathrm{~d}$ shows that ATPase activity decayed exponentially. Differential activity values were obtained from the derivative of the Pi production as function of time (not shown)

These results strongly suggest that this ATPase activity resulted from an NTPDase. Moreover, addition of detergent $\mathrm{C}_{12} \mathrm{E}_{8}$ significantly inhibited the ATPase activity of SMG microsomes (28\% of control, Table 1 ). If this ATPase activity was the product of a SERCA type enzyme, mild detergent solubilization would augment activity by abolishing inhibition by intravesicular $\mathrm{Ca}^{2+}$ concentration. Furthermore, it has been previously described that detergent had a strong inhibitory effect on NTPDase activity (Wang and Guidotti 1998).

Cation and substrate specificity, inhibitors effect, and detergent sensitivity indicate the presence of one or several NTPDases, probably belonging to the NTPDase1 related enzymes (NTPDases 1, 2, 3 and 8), which are usually located in the plasma membrane. However, some papers also reported NTPDase1 activity in subcellular compartments in eukaryotic cells (Zhong et al. 2001, D'Alessio et al. 2003), thus opening the question about the possible intracellular function of these enzymes.

\section{Immunohistochemistry}

Based on the highly conserved amino acid sequence of different NTPDases among species, we tested the specificity of a commercially available antihuman NTPDase1 (hNTPDase1) monoclonal antibody.

Western blot performed under non-reducing conditions PAGE revealed that this antibody was able to recognize a band of $78 \mathrm{kDa}$ in human platelet lysate as well as in rat whole homogenate and microsomal fraction (Fig. 3a, lanes 1-3). It should be noted that $54 \mathrm{kDa}$ bands are proportionally most important in SMG microsomal fraction compared to SMG whole homogenate, indicating that microsomal fraction presented a significant amount of non-glycosylated enzyme (Lemmens et al. 2000). After PNGase F digestion, microsomal fraction showed a reduced $78 \mathrm{kDa}$ band and the presence of a new band of about $28 \mathrm{kDa}$ (Fig. 3, lane 4).

Figures 3b-e show rat SMG immunoreactivity against anti-hNTPDase1 monoclonal antibody. As expected, immunoreactivity was strongly revealed in blood vessels, which are well known to express high levels of NTPDases. Cells of epithelial ducts (Figs 3b,c) and mucous acini (Figs 3b,d) are homogeneously labeled, whereas only $20 \%$ of serous acini were anti hNTPDase1 positive (Figs 3b,e). Figures 3c-e reveal that immunoreactivity was located both in the plasma membrane and in the cytosol of rat SMG cells with stronger reactivity in the plasma membrane of luminal pole (Figs 1c-e, arrow heads). NTPDase immunoreactivity was principally located in the luminal pool of duct cells, whereas labeling in serous and mucous acini is distributed through the 

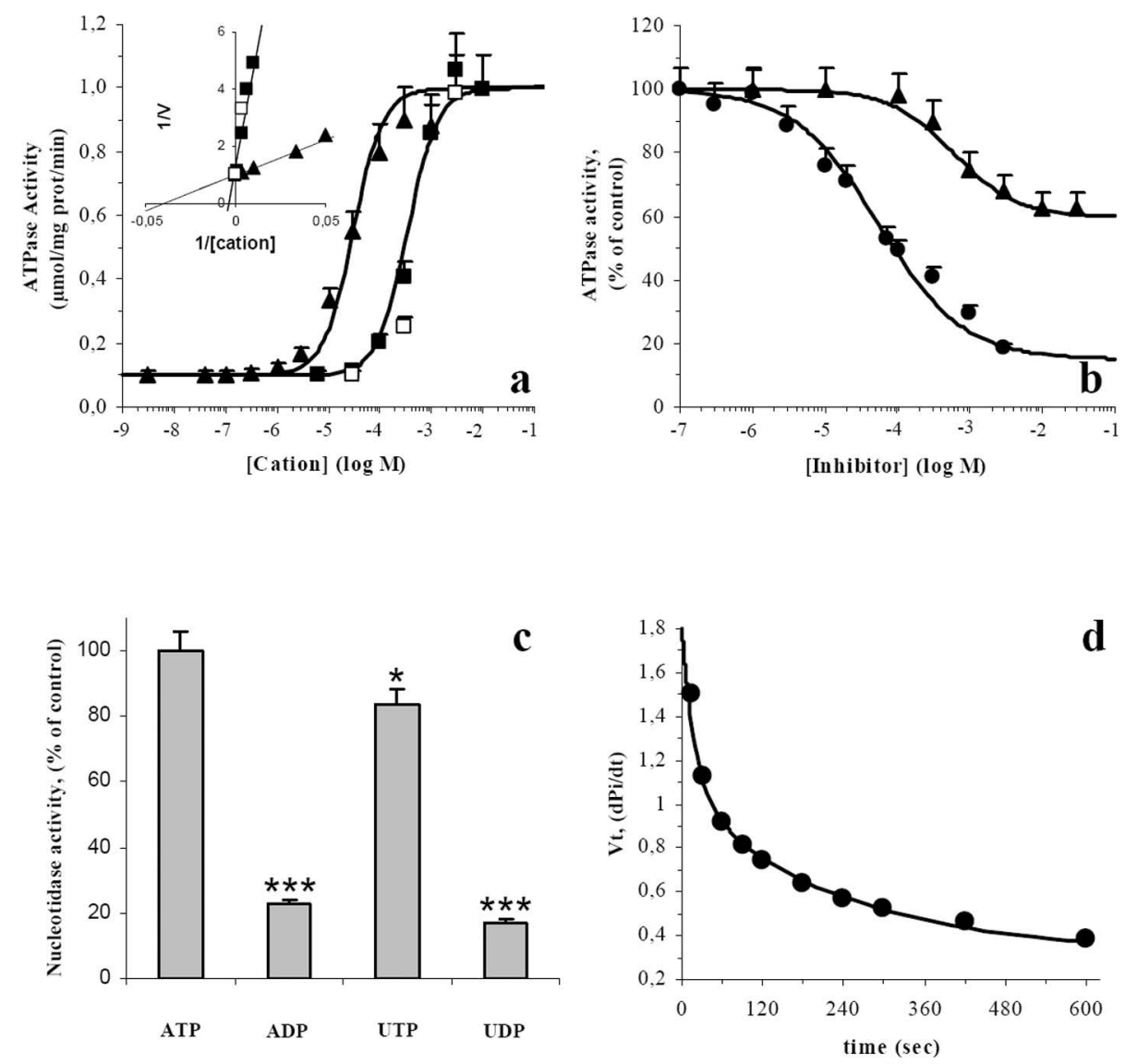

Fig. 2. ATPase activity in rat submandibular microsomes. Cation dependence, inhibitor's action, substrate specificity and time dependence (a) ATPase activity was plotted as function of $\left[\mathrm{Ca}^{2+}\right]$ (triangles) without added $\mathrm{Mg}$, or as function of $\left[\mathrm{Mg}^{2+}\right]$ (filled squares) or $\left[\mathrm{Mn}^{2+}\right]$ (open squares), without added $\mathrm{Ca}$. Experiments were made at $37{ }^{\circ} \mathrm{C}$ with $3 \mathrm{mM}$ ATP. Inset: Lineweaver-Burk double reciprocal plots. (b) Effect of suramin (circles, $\mathrm{IC}_{50}=55 \pm 10 \mu \mathrm{M}$ ) and sodium azide (triangles, $\mathrm{IC}_{50}=585 \pm 160 \mu \mathrm{M}$ ) on nucleotidase activity. (c) Substrate specificity of nucleotidase activity. Control ATPase activity (100\%) was $\quad 1.24 \pm 0.09 \quad \mu \mathrm{mol} / \mathrm{mg}$ protein/min. All substrates were used at $3 \mathrm{mM}\left(0.1 \mathrm{mM} \mathrm{Ca}^{2+}\right)$. (d) ATPase activities were calculated as $\mathrm{dPi} / \mathrm{dt}$ values from the derivative of the curve obtained for $\mathrm{Pi}$ as a function of time. Each point is a result of at least five independent experiments. Results are expressed as mean \pm S.E.M. * $\mathrm{P}<0.05$;*** $\mathrm{P}<0.001$. cells. This difference might be accounted by the nuclear localization of duct cells near the luminal membrane, while acinar cells nuclei are distributed throughout the cytoplasm.

Distribution of NTPDase immunoreactivity presented herein was different from that described in the mouse SMG where mucous acini were weakly stained while duct cells were not reactive to anti CD39 polyclonal antibody at all (Kittel et al. 2004).

\section{Immunofluorescence and colocalization}

Present observations of NTPDase1-like immunoreactivity in the cytosol (Figs 3c-e) suggest localization in the endoplasmic reticulum. This hypothesis was tested by immunofluorescence colocalization experiments using two antibodies reacting to NTPDase1 and to calnexin (specific endoplasmic reticulum protein) (Bergeron et al. 1994). Figure 4 shows anti-calnexin immunoreactivity $(\mathrm{a}, \mathrm{d}, \mathrm{g})$, anti NTPDase1 labeling (b,e,h) and colocalization images (c,f,i) from duct cells $(a, b, c)$, mucous acini $(d, e, f)$ and serous acini $(\mathrm{g}, \mathrm{h}, \mathrm{i})$. The three cell types show positive anti-NTPDase immunofluorescence (red) and a strong reaction to anti- calnexin antibodies (green). Anti-calnexin immunoreactivity presents the typical perinuclear pattern of ER localization.

Colocalization analysis was made using the same fluorescence intensity for both signals and pixel-topixel superposition was only considered as a valid colocalization point. Figure 4 (c,f,i) shows that NTPDase1 immunoreactivity strongly colocalized with calnexin in duct cells (c), mucous acinar cells (f) and serous acinar cells (i).

\section{Discussion}

We studied active $\mathrm{Ca}^{2+}$ transport and ATPase activity in rat submandibular gland using an endoplasmic reticulum enriched microsomes preparation (Hurley and Martinez 1986).

$\mathrm{Ca}^{2+}$-uptake by the microsomes was completely abolished by P-type ATPases or SERCA inhibitors. These results give the first information about specific inhibitor actions on submandibular $\mathrm{Ca}^{2+}$ uptake, and agree with the presence of a SERCA pump in submandibular gland (Lee et al. 1997a). However, both 


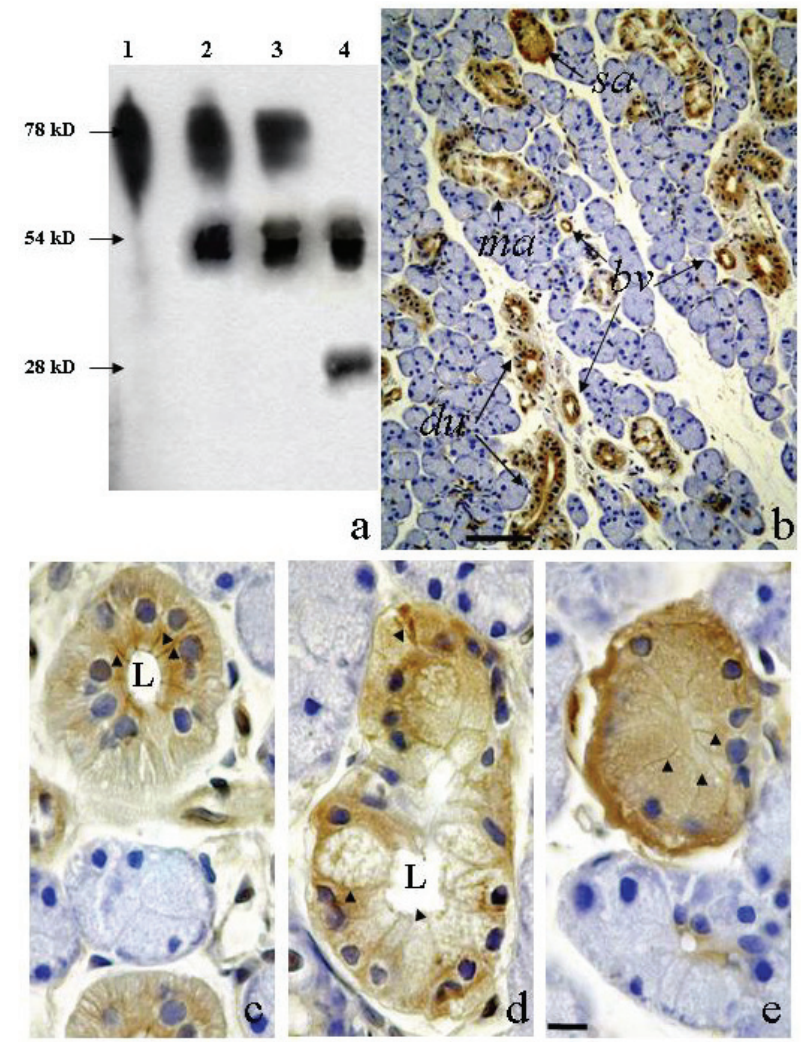

Fig. 3. CD39 immunostaining in rat submandibular gland. (a) cross-reactivity of anti-hNTPDase 1 monoclonal antibody was revealed by Western blot showing positive reactivity with human platelet lysate (lane 1), rat SMG whole homogenate (lane 2), rat SMG microsomes (lane 3) and rat SMG microsomes after deglycosylation by PNGase (lane 4). (b) Brown color of peroxidase-antiperoxidase (PAP) revealed the anti-hNTPDase1 immunoreactive cells in rat SMG counterstained with hematoxylin. Immunoreactivity is present in blood vessels (bv), secretory ducts (du) and mucous acini (ma) but only in some serous acini (sa). Panels $\mathbf{c}, \mathbf{d}$ and $\mathbf{e}$ show cellular localization with a higher magnification, arrow heads indicate strong plasma membrane immunoreactivity. All duct cells were immunoreactive, with apical area strongly labeled (c). Depleted mucous cells (d) and acinar serous cells (e) were uniformly stained. Bars: $(b)=100$ $\mu \mathrm{m},(c, d$, and $e)=10 \mu \mathrm{m}$. L=lumen.

rate and maximal amount of accumulated $\mathrm{Ca}^{2+}$ were lower than those measured in the well-known sarcoplasmic reticulum (SR) from rabbit skeletal muscle (Gonzalez et al. 2003). Since SR contains only the SERCA1 isoform, this difference might result from the expression of SERCA isoforms SERCA3 and SERCA2 in the SMG (Lee et al. 1997a). It is also possible that this difference might be the result of a minor SERCA concentration in microsomes from SMG.

High sensitivity to thapsigargin discards the possibility of a secretory pathway calcium ATPase (SPCA) since, the pumps involved in this process are thapsigargin insensitive (Van Baelen et al. 2004, Vanoevelen et al. 2005).
The mean of the work was to determine whether the ATPase activity measured in the microsomes is only a result of a SERCA activity. In skeletal muscle, addition of calcium ionophore A23187 to impermeable vesicles enriched in SERCA enhances the ATPase activity since it prevents calcium accumulation and consequent ATPase inhibition (Gonzalez et al. 2006). Same effect is usually found by addition of mild detergents, which produces total or partial enzyme solubilization. However, ATPase activity in our vesicles was not modified by ionophore addition, and it was strongly inhibited in the presence of $\mathrm{C}_{12} \mathrm{E}_{8}$. Furthermore, activity was significantly inhibited by sodium azide and by suramin, two drugs that are effective to inhibit NTPDases (Knowles and Nagy 1999, Schetinger et al. 2001, Failer et al. 2003, Iqbal et al. 2005). Simultaneous addition of saturating concentrations of suramin and sodium orthovanadate revealed additive effects, supporting the hypothesis of at least two different ATP-hydrolyzing enzymes in the microsomal preparation.

When characterizing cation dependence of ATPase activity we found that, although having more affinity for calcium, it could be also activated by magnesium or manganese when calcium was absent as described for NTPDases (Mihaylova-Todorova et al. 2002) and SPCA (Van Baelen et al. 2004), respectively. $\mathrm{Km}$ values for these cations were significantly slower than described $\mathrm{Km}$ values in SERCA (Gonzalez et al. 2006) or SPCA (Van Baelen et al. 2004, Vanoevelen et al. 2005), but similar to those reported for NTPDases (Mihaylova-Todorova et al. 2002). The manganese activation was previously described for different plasma membrane Mg-ATPase (Beeler et al. 1985, Zhao and Dhalla 1988) but in those reports activation rates were even lower for Mn compared to Mg. Conversely, results presented herein showed similar activation rates for both cations in accordance with recent data obtained with a Trypanosoma Brucei NTPDase (De Souza Leite et al. 2007).

Microsomes nucleotidase activity had a wide range of substrate specificity, presenting significantly higher hydrolysis rate for nucleotide tri phosphates (ATP and UTP) than for nucleotide diphosphates (ADP and UDP). Finally, ATPase activity decayed as a function of time, as was previously described for Ca-independent Mg-ATPases (Beeler et al. 1995), the Ca/Mg ATPase of rat heart plasma membrane (Zhao and Dhalla 1988) or, more specifically, for human NTPDase2 (Knowles and Chiang 2003). 
All these results support the hypothesis that the endoplasmic reticulum microsomes from rat submandibular gland express at least two different enzymes responsible for calcium uptake and nucleotidase activity. The biochemical characteristics of nucleotidase activity agree with an ecto-nucleoside triphosphate diphosphohydrolase (E-NTPDase) activity (Plesner 1995, Heine et al. 1999, Iqbal et al. 2005, Kukulski et al. 2005).

Eight members of E-NTPDase family have been characterized up to date in several tissues. They hydrolyze nucleoside triphosphates and diphosphates with wide affinity range for different substrates (Zimmermann 2001, Kukulski et al. 2005, Wu et al. 2005). NTPDase1 (CD39), NTPDase2 (CD39L1), NTPDase3 (CD39L3) and NTPDase8 are typical ectoenzymes localized in the plasma membrane (Reviewed in Grinthal and Guidotti 2006), and they could be grouped as NTPDase1 related enzymes. NTPDase1 is the prototype member of this group and it has been described as a detergent-sensitive dimeric active form (Wang et al. 1998) that is usually located in the plasma membrane but that can be also expressed in different cytoplasmic compartments in yeast and mammals (Zhong et al. 2001, D'Alesio et al. 2001, Wang et al. 2005). The other four members of this enzyme family (NTPDase4-7) have a specific intracellular localization (Wang and Guidotti 1998, Mulero et al. 1999, Briederbick et al. 2000).

The presence of a NTPDase in three cellular types of the rat submandibular gland was described using an anti-hNTPDase1 antibody (Fig. 3b-e). This antibody was able to recognize two bands from rat submandibular gland homogenates or microsome preparation (Fig. 3a, lanes 2-3) and was demonstrated to cross react with human platelets (Fig. 3a, lane 1). Moreover, after deglycosylation, microsome preparation presented a third band corresponding to deglycosylated form (Fig. 3a, lane 4). Immunohistochemistry revealed a strong immunoreactivity at the plasma membrane of blood vessels as well as acinar and duct cells. However, there was also important cytosolic anti-NTPDase1 immunoreactivity in salivary cells. Since cytosolic NTPDase localization well correlated with the specific ER marker calnexin (Fig. 4), it could be speculated that NTPDase described herein is one of the four intracellular members of the NTPDase family (NTPDase4-7). The two splicing variants of NTPDase4 (LALP70) hydrolyze a variety of nucleoside tri- and diphosphates and show insignificant catalytic activity towards ATP or ADP as substrates (Wang and Guidotti 1998, Biederbick et al.
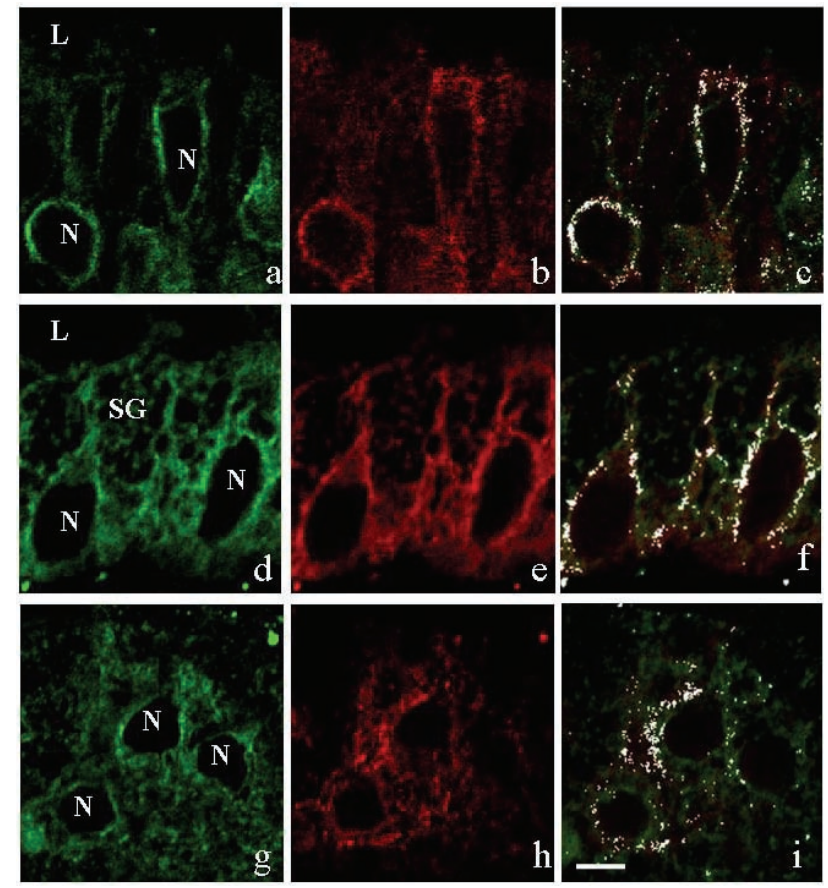

Fig. 4. CD39 and calnexin colocalization by confocal microscopy immunofluorescence. Calnexin immunostaining was revealed by an anti-calnexin Ab coupled to Alexa Fluor 488 (green a, d, g) and that of CD39 by an anti-CD39 monoclonal Ab coupled to Alexa 546 (red b, e, h). Cytoplasmic anti-calnexin immunoreactivity was found in duct cells (a), mucous acinar cells (d) and serous acinar cells (g). Duct (b), mucous (e) and serous (h) cells were anti CD39 immunostained. White points in figures c, f, and $\mathbf{i}$ indicate that both proteins colocalize at a narrow perinuclear area. L - lumen, N - nucleus, SG - secretory granules. Bar $=5 \mu \mathrm{m}$.

2000). ER- and Golgi-allocated NTPDase5 (CD39L4) and NTPDase6 (CD39L2) preferentially hydrolyze nucleoside diphosphate (Trombetta \& Helenius 1999, Mulero et al. 1999, Braun et al. 2000). Finally, NTPDase7 (LALP1) has an intracellular membranes distribution and hydrolyzes a variety of nucleoside triand diphosphates with a higher preference for UTP than for ATP (Shi et al. 2001). The substrate specificity of nucleotidase activity measured in submandibular gland microsomes (Fig. 2c) excludes the hypothesis that main activity was the product of any of these intracellular isoforms. The other members of NTPDase family are usually found in the plasma membrane. However, Zhong et al. (2001) demonstrated that, when transfected with a CD39-like apyrase, Cos7 cells presented this enzyme in the endoplasmic reticulum. It should be taking into account that maturation process of several plasma membrane proteins occurs in the ER. These authors showed an incomplete glycosylation pattern and a reduced activity (Zhong et al. 2001). Present results support the hypothesis that this may be the case in ER 
enriched fractions from rat SMG. Indeed, (i) the NTPDase activity of SMG microsomal ER-enriched fraction was tenfold lower than recently reported NTPDase activity from rat SMG acinar cells (Henz et al. 2006) and (ii) we observed the presence of a $54 \mathrm{kDa}$ band corresponding to a deglycosylated form of the enzyme in the ER, compared with the $78 \mathrm{kDa}$ band (glycosylated protein) which is the most abundant form in the whole homogenate of SMG (Fig. 3a, lanes 2-4). Suramin inhibition pattern and substrate specificity could indicate the presence of an NTPDase2 or NTPDase3 (Iqbal et al. 2005, Kukulski et al. 2005), but biochemical characterization of NTPDase activity is not enough to distinguish among NTPDases 1, 2, 3 or 8 .

The question about the putative function of this NTPDase in the ER of SMG remains open since, on one hand, it was proposed that high nucleotidase activity in the intracellular compartments could deplete ATP and potentially inhibit other ATP-dependent components and processes (Braakman et al. 1992), but on the other hand, the presence of an active intracellular NTPDase activity was associated with several secretory processes. It was found in secreted vesicles observed in the lumen of pancreatic acini (Beaudoin et al. 1986) as well as in the pancreatic juice (Yegutkin et al. 2006), the oviduct (Rosenberg et al. 1977, Knowles and Nagy 1999) and the prostatic fluid (Ronquist and Brody 1985). NTPDases could play an important role in vesicle trafficking and protein glycosylation (Trombetta and Helenius 1999, Beaudoin et al. 1986) by modifying substrate concentrations which regulate activities of enzymes involved in these processes. This hypothesis is supported by NTPDase distribution in SMG, where ductal and mucous acinar cells are directly involved in the secretory process of highly glycosylated mucins. Another nonexclusive hypothesis is that functional NTPDases from submandibular ER might play an active role in regulation of ATP concentration in duct saliva. It was recently demonstrated that ATP is secreted by pancreatic acinar cells and that ATP concentration is modified during its passage through the ductal system by the action of NTPDase-like enzymes secreted to ductal lumen (Yegutkin et al. 2006). Luminal ATP concentration is crucial to control calcium signal triggered by purinergic receptor (P2R). Indeed, it was demonstrated in both pancreatic and salivary acinar and duct cells that expression and sensitivity of P2R were heterogeneous (Lee et al. 1997c, Li et al. 2003, Yegutkin et al. 2006), with predominant expression of ATP/UTP-sensitive receptors compared to ADP/UDP-sensitive receptors in duct cells.

Our results demonstrated that both SERCA and NTPDase like enzymes are present in submandibular gland ER. The former is responsible to calcium uptake restoring cytosolic calcium to baseline levels before stimulation. The later could be involved in the control of ductal ATP concentration which, in turns, would modulate purinergic signaling cascade.

\section{Conflict of Interest}

There is no conflict of interest.

\section{Acknowledgements}

This work was supported by the Institut National de la Santé et de la Recherche Médicale (INSERM), the Centre National de la Recherche Scientifique (CNRS), and grants from the Universidad de Buenos Aires (OD027) and the CONICET from Argentina (PIP02503). M. A. Ostuni was the recipient of doctoral fellowship from the Universidad de Buenos Aires and a postdoctoral fellow from the INSERM. The authors are grateful to Dr. B. Vidic for helpful discussions and careful reading of the manuscript, Dr. E. Ogier-Denis for kindly providing anti-calnexin antibody, and Dr. M. JandrotPerrus for kindly providing human platelets lysate.

\section{References}

ALONSO GL, BAZERQUE PM, ARRIGO DM, TUMILASCI OR: Adenosine triphosphate-dependent calcium uptake by rat submaxillary gland microsomes. J Gen Physiol 58: 340-350, 1971.

BAGINSKI ES, FOA PP, ZAK B: Microdetermination of inorganic phosphate, phospholipids, and total phosphate in biologic materials. Clin Chem 13: 326-332, 1967.

BEAUDOIN AR, VACHEREAU A, GRONDIN G, ST JEAN P, ROSENBERG MD, STROBEL R: Microvesicular secretion, a mode of cell secretion associated with the presence of an ATP-diphosphohydrolase. FEBS Lett 203: 1-2, 1986. 
BEELER TJ, WANG T, GABLE K, LEE S: Comparison of the rat microsomal Mg-ATPase of various tissues. Arch Biochem Biophys 243: 644-654, 1985.

BERGERON JJ, BRENNER MB, THOMAS DY, WILLIAMS DB: Calnexin: a membrane-bound chaperone of the endoplasmic reticulum. Trends Biochem Sci 19: 124-128, 1994.

BIEDERBICK A, KOSAN C, KUNZ J, ELSASSER HP: First apyrase splice variants have different enzymatic properties. J Biol Chem 275: 19018-19024, 2000.

BRAAKMAN I, HELENIUS J, HELENIUS A: Role of ATP and disulphide bonds during protein folding in the endoplasmic reticulum. Nature 356: 260-262, 1992.

BRAUN N, FENGLER S, EBELING C, SERVOS J, ZIMMERMANN H: Sequencing, functional expression and characterization of rat NTPDase6, a nucleoside diphosphatase and novel member of the ecto-nucleoside triphosphate diphosphohydrolase family. Biochem J 351: 639-647, 2000.

D'ALESSIO C, TROMBETTA ES, PARODI AJ: Nucleoside diphosphatase and glycosyltransferase activities can localize to different subcellular compartments in Schizosaccharomyces pombe. J Biol Chem 278: 22379$22387,2003$.

DE SOUZA LEITE M, THOMAZ R, FONSECA FV, PANIZZUTTI R, VERCESI AE, MEYER-FERNANDES JR: Trypanosoma brucei brucei: biochemical characterization of ecto-nucleoside triphosphate diphosphohydrolase activities. Exp Parasitol 115: 315-323, 2006.

DOWD FJ, PASIENIUK JA, HAND AR, CHEUNG PH, HAINES DW: Characteristics of anion-stimulated MgATPase from rat parotid gland secretory granules. Arch Oral Biol 34: 167-176, 1989.

DOWD FJ, LI LS, CAMPBELL JE, CHEUNG PH: Localization and characterization of a parotid $\mathrm{Ca}^{2+}$-dependent ectoATPase. Crit Rev Oral Biol Med 4: 415-419, 1993.

DOWD FJ, MURPHY HC, LI L: Metabolism of extracellular ATP by rat parotid cells. Arch Oral Biol 41: 855-862, 1996.

DOWD FJ, LI LS, ZENG W: Inhibition of rat parotid ecto-ATPase activity. Arch Oral Biol 44: 1055-1062, 1999.

FABIATO A, FABIATO F: Calculator programs for computing the composition of the solutions containing multiple metals and ligands used for experiments in skinned muscle cells. J Physiol (Paris) 75: 463-505, 1979.

FAILER BU, ASCHRAFI A, SCHMALZING G, ZIMMERMANN H: Determination of native oligomeric state and substrate specificity of rat NTPDase1 and NTPDase2 after heterologous expression in Xenopus oocytes. Eur $J$ Biochem 270: 1802-1809, 2003.

GONZALEZ DA, OSTUNI MA, LACAPERE JJ, ALONSO GL: A model accounting for the simultaneous transport of calcium and manganese in sarcoplasmic reticulum membranes. Ann N Y Acad Sci 986: 320-322, 2003.

GONZALEZ DA, OSTUNI MA, LACAPERE JJ, ALONSO GL: Stoichiometry of ATP and metal cofactor interaction with the sarcoplasmic reticulum $\mathrm{Ca}^{2+}$-ATPase: a binding model accounting for radioisotopic and fluorescence results. Biophys Chem 124: 27-34, 2006.

GRINTHAL A, GUIDOTTI G: CD39, NTPDase 1, is attached to the plasma membrane by two transmembrane domains. Why? Purinergic Signal 2: 391-398, 2006.

HENZ SL, RIBEIRO CG, ROSA A, CHIARELLI RA, CASIALI EA, SARKIS JJ: Kinetic characterization of ATP diphosphohydrolase and 5'-nucleotidase activities in cells cultured from submandibular salivary glands of rats. Cell Biol Int 30: 214-220, 2006.

HURLEY TW, MARTINEZ JR: Characterization of the kinetic and regulatory properties of high-affinity $\mathrm{Ca}^{2+}$-ATPase activity in acinar preparations of rat submandibular salivary glands. Arch Oral Biol 30: 587-594, 1985.

HURLEY TW, MARTINEZ JR: Characterization and localization of two forms of active $\mathrm{Ca}^{2+}$ transport in vesicles derived from rat submandibular glands. Cell Calcium 7: 49-59, 1986.

HURLEY TW, RYAN MP: The control of cytosolic $\mathrm{Ca}^{2+}$ concentration: studies of high affinity $\mathrm{Ca}^{2+}$ transport in permeabilized acini of rat submandibular glands. Arch Oral Biol 33: 793-800, 1988.

IQBAL J, VOLLMAYER P, BRAUN N, ZIMMERMANN H, MULLER CE: A capillary electrophoresis method for the characterization of ecto-nucleoside triphosphate diphosphohydrolases (NTPDases) and the analysis of inhibitors by in-capillary enzymatic microreaction. Purinergic Signal 1: 349-358, 2005. 
KITTEL A, PELlETIER J, BIGONNESSE F, GUCKELBERGER O, KORDAS K, BRAUN N, ROBSON SC, SEVIGNY J: Localization of nucleoside triphosphate diphosphohydrolase-1 (NTPDase1) and NTPDase2 in pancreas and salivary gland. J Histochem Cytochem 52: 861-871, 2004.

KNOWLES AF, NAGY AK: Inhibition of an ecto-ATP-diphosphohydrolase by azide. Eur J Biochem 262: 349-357, 1999.

KNOWLES AF, CHIANG W-C: enzymatic and transcriptional regulation of human ecto-ATPase/E-NTPDase 2. Arch Biochem Biophys 418: 217-227, 2003.

KUKULSKI F, LEVESQUE SA, LAVOIE EG, LECKA J, BIGONNESSE F, KNOWLES AF, ROBSON SC, KIRLEY TL, SEVIGNY J: Comparative hydrolysis of P2 receptor agonists by NTPDases 1, 2, 3 and 8. Purinergic Signal 1: 193-204, 2005.

LAEMMLI UK: Cleavage of structural proteins during the assembly of the head of bacteriophage T4. Nature 227: 680$685,1970$.

LEE MG, XU X, ZENG W, DIAZ J, KUO TH, WUYTACK F, RACYMAEKERS L, MUALLEM S: Polarized expression of $\mathrm{Ca}^{2+}$ pumps in pancreatic and salivary gland cells. Role in initiation and propagation of $\left[\mathrm{Ca}^{2+}\right] \mathrm{i}$ waves. J Biol Chem 272: 15771-15776, 1997a.

LEE MG, XU X, ZENG W, DIAZ J, WOJCIKIEWICZ RJ, KUO TH, WUYTACK F, RACYMAEKERS L, MUALLEM S: Polarized expression of $\mathrm{Ca}^{2+}$ channels in pancreatic and salivary gland cells. Correlation with initiation and propagation of $\left[\mathrm{Ca}^{2+}\right]$ i waves. J Biol Chem 272: 15765-15770, 1997b.

LEE MG, ZENG W, MUALLEM S: Characterization and localization of P2 receptors in rat submandibular gland acinar and duct cells. J Biol Chem 272: 32951-3295, 1997c.

LEMMENS R, KUPERS L, SEVIGNY J, BEAUDOIN AR, GRONDIN G, KITTEL A, WAELKENS E, VANDUFFEL L: Purification, characterization, and localization of an ATP diphosphohydrolase in porcine kidney. Am J Physiol 278: F978-F988, 2000.

LI Q, LUO X, ZENG W, MUALLEM S: Cell-specific behavior of P2X7 receptors in mouse parotid acinar and duct cells. J Biol Chem 278: 47554-47561, 2003.

MIHAYLOVA-TODOROVA ST, TODOROV LD, WESTFALL DP: Enzyme kinetics and pharmacological characterization of nucleotidases released from the guinea pig isolated vas deferens during nerve stimulation: evidence for a soluble ecto-nucleoside triphosphate diphosphohydrolase-like ATPase and a soluble ecto-5'-nucleotidase-like AMPase. J Pharmacol Exp Ther 302: 992-1001, 2002.

MULERO JJ, YEUNG G, NELKEN ST, FORD JE: CD39-L4 is a secreted human apyrase, specific for the hydrolysis of nucleoside diphosphates. J Biol Chem 274: 20064-20067, 1999.

MURPHY HC, HAND AR, DOWD FJ: Localization of an ecto-ATPase/cell-CAM 105 (C-CAM) in the rat parotid and submandibular glands. J Histochem Cytochem 42: 561-568, 1994.

PLESNER L: Ecto-ATPases: identities and functions. Int Rev Cytol 158: 141-214, 1995.

ROBSON SC, SEVIGNY J, ZIMMERMANN H: The E-NTPDase family of ectonucleotidases: structure function relationships and pathophysiological significance. Purinergic Signal 2: 409-430, 2006.

RONQUIST G, BRODY I: The prostasome: its secretion and function in man. Biochim Biophys Acta 822: 203-218, 1985.

ROSENBERG MD, GUSOVSKY T, CUTLER B, BERLINER AF, ANDERSON B: Purification and characterization of an extracellular ATPase from oviductal secretions. Biochim Biophys Acta 482: 197-212, 1977.

SCHETINGER MR, VIEIRA VL, MORSCH VM, BALZ D: ATP and ADP hydrolysis in fish, chicken and rat synaptosomes. Comp Biochem Physiol B Biochem Mol Biol 128: 731-741, 2001.

SHI JD, KUKAR T, WANG CY, LI QZ, CRUZ PE, DAVOODI-SEMIROMI A, YANG P, GU Y, LIAN W, WU DH, SHE JX: Molecular cloning and characterization of a novel mammalian endo-apyrase (LALP1). J Biol Chem 276: 17474-17478, 2001.

TEO TS, THIYAGARAJAH P, LEE MK, SELWYN MJ: The high-affinity $\mathrm{Ca}^{2+}$-ATPase from rat parotid plasma membranes is an ectoenzyme: solubilization and characterization of the $\mathrm{Ca}^{2+}$-ATPase activity. Biochem Med Metab Biol 50: 358-362, 1993. 
TROMBETTA ES, HELENIUS A: Glycoprotein reglucosylation and nucleotide sugar utilization in the secretory pathway: identification of a nucleoside diphosphatase in the endoplasmic reticulum. EMBO J 18: 3282-3292, 1999.

VALENZUELA MA, LOPEZ J, DEPIX M, MANCILLA M, KETTLUN AM, CATALAN L, CHIONG M, GARRIDO J, TRAVERSO-CORI A: Comparative subcellular distribution of apyrase from animal and plant sources. Characterization of microsomal apyrase. Comp Biochem Physiol B 93: 911-919, 1989.

VAN BAELEN K, DODE L, VANOEVELEN J, CALlEWAERT G, De SMEDT H, MiSSIAEN L, PARYS JB, RAEYMAEKERS L, WUYTACK F: The $\mathrm{Ca}^{2+} / \mathrm{Mn}^{2+}$ pumps in the Golgi apparatus. Biochim Biophys Acta 1742: 103-112, 2004.

VANOEVELEN J, DODE L, VAN BAELEN K, FAIRCLOUGH RJ, MISSIAEN L, RAEYMAEKERS L, WUYTACK F: The secretory pathway $\mathrm{Ca}^{2+} / \mathrm{Mn}^{2+}$-ATPase 2 is a Golgi-localized pump with high affinity for $\mathrm{Ca}^{2+}$ ions. J Biol Chem 280: 22800-22808, 2005.

WANG CJ, VLAJKOVIC SM, HOUSLEY GD, BRAUN N, ZIMMERMANN H, ROBSON SC, SEVIGNY J, SOELLER C, THORNE PR: C-terminal splicing of NTPDase2 provides distinctive catalytic properties, cellular distribution and enzyme regulation. Biochem J 385: 729-736, 2005.

WANG TF, GUIDOTTI G: Golgi localization and functional expression of human uridine diphosphatase. $J$ Biol Chem 273: 11392-11399, 1998.

WANG TF, OU Y, GUIDOTTI G: The transmembrane domains of ectoapyrase (CD39) affect its enzymatic activity and quaternary structure. $J$ Biol Chem 273: 24814-24821, 1998.

WU JJ, CHOI LE, GUIDOTTI G: N-linked oligosaccharides affect the enzymatic activity of CD39: diverse interactions between seven N-linked glycosylation sites. Mol Biol Cell 16: 1661-1672, 2005.

YEGUTKIN GG, SAMBURSKI SS, JALKANEN S, NOVAK I: ATP-consuming and ATP-generating enzymes secreted by pancreas. J Biol Chem 281: 29441-29447, 2006.

ZHAO D, DHALLA NS: Characterization of rat heart plasma membrane $\mathrm{Ca}^{2+} / \mathrm{Mg}^{2+}$ ATPase. Arch Biochem Biophys 263: 281-292, 1988.

ZHONG X, MALHOTRA R, WOODRUFF R, GUIDOTTI G: Mammalian plasma membrane ecto-nucleoside triphosphate diphosphohydrolase $1, \mathrm{CD} 39$, is not active intracellularly. The N-glycosylation state of CD39 correlates with surface activity and localization. J Biol Chem 276: 41518-41525, 2001.

ZIMMERMANN H: Purinergic and pyrimidergic signalling I. In: Handbook of Experimental Pharmacology. ABBRACCIIO MP, WILLIAMS M (ed), Springer Verlag, Heidelberg, 2001, pp 209-250. 